\title{
A Cross - Section Study to Determine Human Height Using Femur Length in Zambian Population
}

\section{Chansa Mulenga ${ }^{1-4 *}$}

${ }^{1}$ Registrar General Surgery Ndola teaching Hospital Zambia, Zambia

${ }^{2}$ MBCHB- Copperbelt University, Zambia

${ }^{3}$ BSC Pharmacy-University of Zambia, Zambia

${ }^{4}$ MSC Anatomy- Copperbelt University, Zambia

*Corresponding Author: Chansa Mulenga, Registrar General Surgery Ndola teaching Hospital Zambia, Zambia.

Received: September 10, 2019; Published: October 15, 2019

DOI: 10.31080/ASMI.2019.02.0399

\begin{abstract}
Introduction: Height estimation from skeletal remains is a useful tool in forensic medicine and biological anthropology. In mass disasters like explosions, railway and aircraft accidents identification is difficult by routine methods and only part of body that can help in identification of skeleton as only a part of it will be available.

In contrast to most advanced countries where extensive works has been done on correlation of measurements of various body parts, documented skeleton remains are not available in Africa for establishing the norms of stature reconstruction. Each race requires its own formula for estimation of stature since there lies variations in the length of limb bones relative to stature, race, sex, climate, heredity and nutritional status.

Methodology: This thesis explores the estimation of a person's height by analysing the femur length in living subjects of medical students from the Copperbelt University Michael Chilufya Sata School of medicine, Copperbelt province of Ndola, Zambia from January 2018 to April 2018.

Findings: The study included a total number of 100 medical students, males $n=50$ and females $n=50$.

The mean femur length and height was $44.2 \mathrm{~cm}$ and $171.6 \mathrm{~cm}$ respectively for the males, while the mean femur length and height was $42.3 \mathrm{~cm}$ and $166.5 \mathrm{~cm}$ respectively for females. The mean femur/height percentage for males $25.7 \%$ and that of females was $25.4 \%$, this indicates that height of individuals is four times the femur.

The mean femur length was $44.2 \mathrm{~cm}$ and $42.3 \mathrm{~cm}$ for males and females respectively, with positive correlation coefficients ( $\mathrm{r}$ ) of 0.5 and 0.64 for male and female femur, implying that males are likely to be taller than women as the femur length is directly proportional to the height.

Conclusion: The height of a person is directly proportional to the femur length and is four times the femur length.

Height estimation differs between males and females in that males are more likely to be taller than women as they have a longer femur length therefore the longer the femur the taller the person and vice versa and hence a different regression formula for height estimation each sex.

Keywords: Human; Population; Femur Length
\end{abstract}

\section{Introduction}

Height estimation from skeletal remains is a useful tool in forensic medicine and biological anthropology [1]. Body stature is measured as one of the key parameters for personal identification; stature reconstruction plays an essential role in the identification of individuals and establishes relationship between stature and dimensions of various body parts. The identity of the dead and mutilated is an essential part of medico-legal and various social reasons $[2,3]$.

In mass disasters like explosions, railway and aircraft accidents identification is difficult by routine methods and only part of body that can help in identification of skeleton as at least a part of it will be available.
Many studies have been conducted on the estimation of stature from various body parts like hands, trunk, intact vertebral column, upper and lower limbs, individual long and short bones, foot and footprints [3]. Extensive works has been done on correlation of measurements of various body parts with stature of a person in Asia and many European countries [4].

In contrast to most advanced countries, documented skeleton remains are not available in Africa for establishing the norms of stature reconstruction. Each race requires its own formula for estimation of stature since there lies variations in the length of limb bones relative to stature, race, sex, climate, heredity and nutritional status. 
The present study was undertaken because at present we depend on foreign formulas done for femur height estimation in Europe and Asian countries, but studies could not be found that are done on the African population, if they are available then they could be relatively few and secondly with improved socioeconomic conditions the height of new generation is increasing, the population is getting taller and therefore relationship between height and length of long bones may have changed, therefore fresh formulae are needed for each generation.

The aim of the study was to correlate length of right and left femur in males and females with the body height and thus estimate height by derived regression formula. The findings of this research will be a contribution to knowledge on medico-legal for the identity of the dead and mutilated in stature reconstruction and will play an essential role in the identification of individuals to establish relationship between stature and dimensions of various body parts in this country as it is a research done on the local population.

The knowledge of the relationship between femoral length and height that will be derived from this research will lay a foundation from which future similar researches could be based.

The human species is distinguished from the non-human primates by several anatomical features. Among these are proportions of the arms and legs relative to total body length. The human difference is illustrated in figure 1 . In proportion to total body length, measured as stature, modern human adults have relatively long legs and short arms as compare to chimpanzees (Pan troglodytes), and bonobos (Pan paniscus).

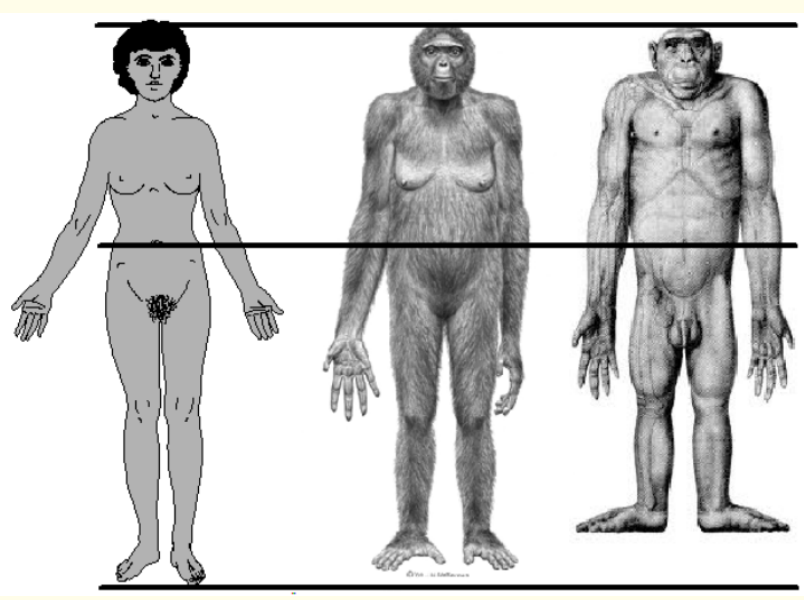

Figure 1

\section{Literature Review}

Study by Rameswarapu Suman Babu et al in titled estimation of body stature using femur length in south Indian population showed the development of specific osteometric standards for stature determination from the femur of South Indian population with satisfactory accuracy. The study concluded that femur inter trochanteric crest length can be used as better alternative variable for estimating body stature length using regression formulae [5].

Height Estimation from Skeletal Project in Biomedicine at ADBOU - University of Southern Denmark using linear regressions showed a strong correlation between the height and femur [6].

The first researcher to analyze Pearson's statistical method was Stevenson in 1929, who found that the European equations could not be successfully applied to a Chinese population as they failed to provide a satisfactory prediction. Pearson's regression study was the first 'mathematical model' and contributed momentously to the advancement of stature estimation because he recognized a range of limitations within stature estimation such as ancestral differences, sex differences. Pearson developed the use of statistical regression, the method that is still used today. The benefit of using an equation rather than a reference table allows the height of an individual to be estimated in cases where a particular femoral length is not present in a table [7].

The correlation coefficients from Tirup and Lille Sct. Mikkelsgade study both showed a great association between femur length and height but the correlation coefficients for women from all three places are lower than that of men [8].

\section{Objectives}

\section{General objectives}

To analyze the relationship between height and lower limb femur length.

\section{Specific objectives}

1. To show the demographic information of the study population

2. To determine the relationship between height and femoral length in the study population

3. To determine the relationship between height and femoral length in relation to sex

\section{Methodology}

Study design

- This cross sectional study was conducted on 100 undergraduate medical students from the Copperbelt University Micheal Chilufya Sata medical school, Copperbelt province of Ndola Zambia this included 50 males and 50 females, after taking their informed consent for a period of 4 months from January 2018 to April 2018.

- The study included respondents of the age range 20 to 40 years.

\section{Inclusion criteria}

Participants were randomly selected, who included medical student encountered at the Copperbelt University Micheal Chilufya Sata medical school and willing to take part in the study. 


\section{Exclusion criteria}

The participants with any obvious congenital or acquired deformity of the leg, achondroplasia or any other congenital or hereditary bony disease were excluded from the study.

\section{Measurement method/Data collection}

The height was measured in a standing position in bare feet flat measured from the top of the round head to the ground floor.

The the femur length was measured with the subject sitting on a straight-backed chair with the spine aganist the chair back, the fermur length was measure between the chair back and the knee.

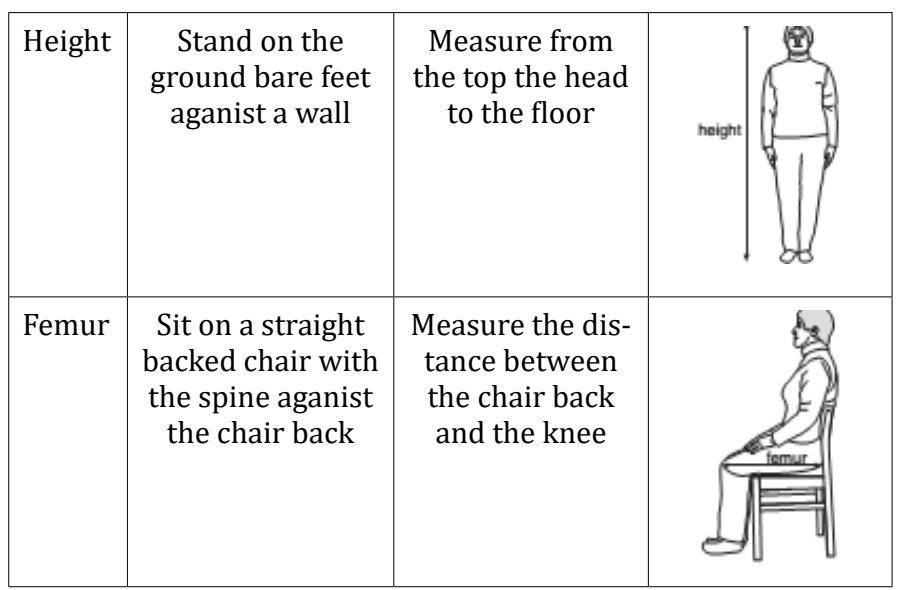

Table 1

\section{Statistical analysis}

The measurements obtained were analysed using excel software.

To obtain the regression equation, the independent parameters in the samples were represented by lower limb (femur length) parameters $\mathrm{X}$-axis and the dependant parameter the Y-axis being the (total height of a person). Plotting the points on a graph to get the equation of a line $y=a+b x$, where $a$ is a constant and $b$ is the slope of a line representing the regression coefficient.

The prediction of a significant relationship amongst the pair of variables was determined by the "Correlation coefficient" i.e., Pearson's ' $r$ '.

\section{Work Plan}

\begin{tabular}{|l|c|c|}
\hline No & Description & Period \\
\hline 1 & Proposal development & January , 2018 \\
\hline 2 & Data collection & February-April 2018 \\
\hline 3 & $\begin{array}{c}\text { Data analysis/Presentations of } \\
\text { Research findings }\end{array}$ & May - December 2018 \\
\hline
\end{tabular}

\section{Table a}

Budget

\begin{tabular}{|l|c|c|}
\hline No & Description & Amount ( ZMK) \\
\hline 1 & Stationary/Printing & 1,000 \\
\hline 4 & Data collection & 1,000 \\
\hline 5 & Data analysis & 2,000 \\
\hline 7 & Total & 4,000 \\
\hline
\end{tabular}

Table b
Results

Demographic data

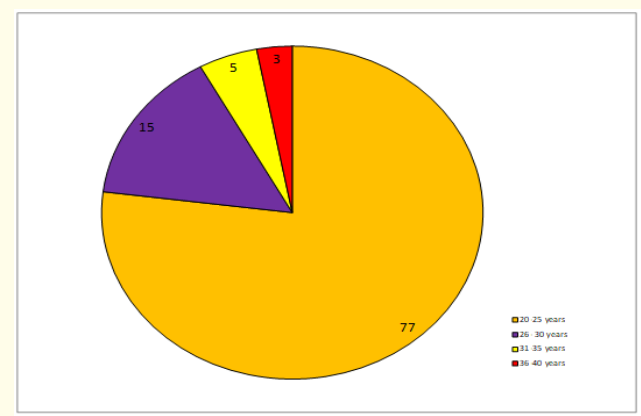

Figure 2: Pie chart showing the Age in relation to the number of students $n=100$ students.

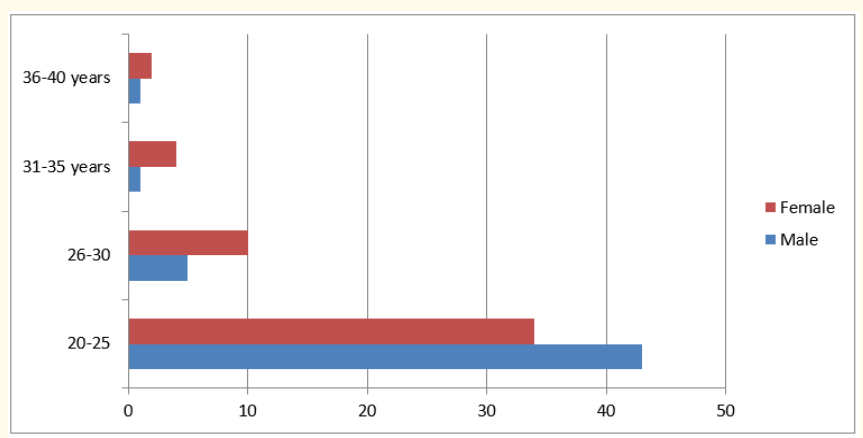

Figure 3: Age and Sex Distribution from 100, male $(\mathrm{n}=50)$ and female $(\mathrm{n}=50)$ individuals.

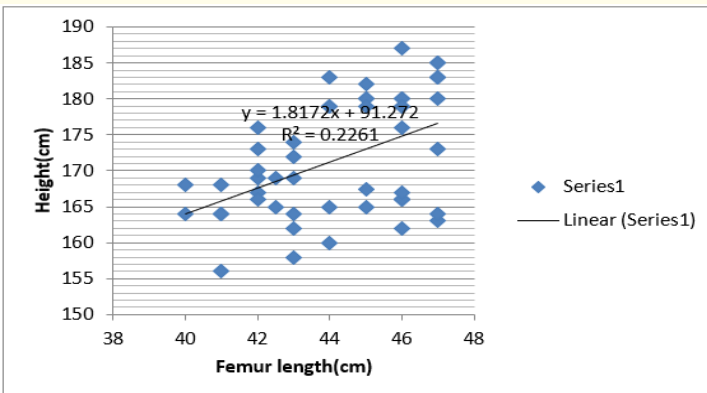

Figure 4: Scatter diagram showing correlation between femur and height in males.

Height $=1.8172$ femur +91.272

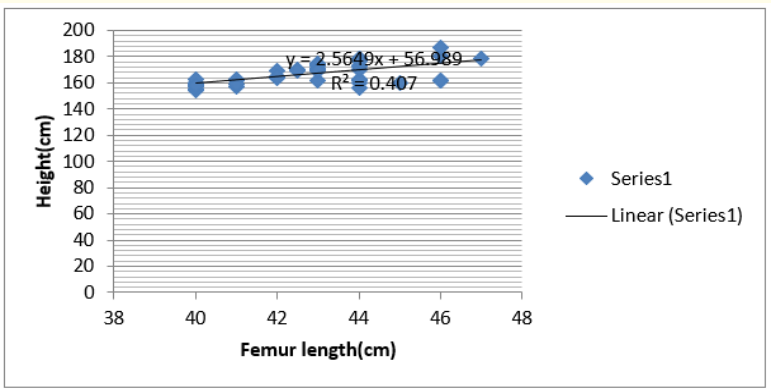

Figure 5: Scatter diagram showing correlation between femur and height in females.

Height $=2.5649$ femur +56.989 


\begin{tabular}{|l|c|c|c|c|}
\hline Description & Mean Femur length (cm) & Mean Height (cm) & Femur/height (\%) & Correlation coefficient ' $r$ ' \\
\hline Males & 44.2 & 171.6 & $25.7 \%$ & 0.5 \\
\hline Females & 42.3 & 166.5 & $25 \%$ & 0.64 \\
\hline
\end{tabular}

Table 2: Femur length in relation to Height and Sex.

\section{Discussion}

Demographics

The study was conducted with 100 undergraduate medical students from the Micheal chilufya Sata School of Medicine Copperbelt University of Ndola Zambia, the student population is a diverse group consisting of people from all corners of the country. These inc1uded 50 males and 50 females, the age distribution of the respondents ranged between 20 and 40 years, with most of the respondents being in the age range of 20-25 years who were 77 , those in the age range 26- 30 were 15 , those in the range 31-35 were 5 and those in age range 36-40 were 3 .

\section{Femoral length in relation to height}

The mean femur length and height was $44.2 \mathrm{~cm}$ and $171.6 \mathrm{~cm}$ respectively for the males, while the female femur length and height was $42.3 \mathrm{~cm}$ and $166.5 \mathrm{~cm}$ respectively. The mean femur/height percentage for males was $25.7 \%$ and that of females being $25.4 \%$; this indicates that height of individuals is four times the femur.

Femoral length in relation to height and sex

The mean femur length was $44.2 \mathrm{~cm}$ and $42.3 \mathrm{~cm}$ for males and females respectively implying that males are likely to be taller than women as the femur length is directly proportional to the height.

The correlation coefficients obtained were $(\mathrm{r})$ of 0.5 and 0.64 for male and female femur this positive correlation coefficients indicated that femur of the human correlates directly with the height, increase in the femur length represents increase in the height of a person.

While these linear regressions both had strong linear correlation, and therefore are valid, it was interesting to compare the constants to other investigations of same character. The constants of the linear regressions were compared to two similar investigations carried out on material from the cemetery of Tirup and Lille Sct. Mikkelsgade. The correlation coefficients obtained were 0.99 and 0.77 for males and females respectively which were both positive in conformity with our findings but the Tirup and Lille Sct. Mikkelsgade coefficients showed a more stronger relationship as the range is from negative to positive with +1 indicating very strong relationship between femur length and height.

Scatter plots were made to determine the regression equations for males and females, regression equations obtained showed a slope of 1.817 and 2.564 males and females respectively indicating that height estimation is different in males and females. These equations being; Height $=1.8172$ femur +91.272 and Height $=$ 2.5649 femur +56.989 for males and females respectively from this study. The findings of this thesis were compared to the study by the ABDOU University southern Denmark by mette wod 2008 on height estimation from skeletal remains;

The regression for calculating the height from the femur was: Height $=2.610$ femur +44.201 and Height $=2.019$ femur +67.579 for males and females respectively, indicating that regression equations for males and females are different.

\section{Conclusion}

The height of a person is directly proportional to the femur length and is four times the femur length, therefore the longer the femur the taller the person and vice versa.

Height estimation differs between males and females in that males are more likely to be taller than women as they have a longer femur length, hence a different regression formula for height estimation.

Regression equation formula for height estimation can be derived by analyzing known individual's femur lengths.

\section{Limitations}

- The study included only participants from the age of 20-40 years, it did not capture very young and older population.

\section{Acknowledgements}

The completion of a thesis has proved to be a grueling process, one that I would not have been able to complete on my own. Those who have supported me, my family and friends, I cannot thank you enough, I am so grateful for your patience, generosity and support.

To my supervisor and mentor Professor Kasonde Bowa thank you so much for your advice and guidance, this thesis is a result of a combined effort and would not be the same without your assistance.

\section{Bibliography}

1. Basant Lal Sirohiwal., et al. "Critics and Sceptics of Medicolegal Autopsy Guidelinesin Indian Context". Journal of Indian Academy of Forensic Medicine 35 (2013): 4.

2. Amit A. Mehta., et al. "Estimation of Stature from Ulna". IJAR 3 (2015): 1156-1158. 
3. Partha Pratim Mukhopadhyay., et al. "Correlation between Maximum Femoral Length and Epicondylar Breadth and Its Application in Stature Estimation: A Population-Specific Study in Indian Bengali Males". Journal of Indian Academy of Forensic Medicine (2010): 32.

4. Lundy JK. "The mathematical versus anatomical methods of stature estimate from long bones". The American Journal of Forensic Medicine and Pathology 6 (1985): 73-76.

5. Rameswarapu Suman Babu. "Estimation of Body Stature Using Fore Arm Bone (ulna) - A Cross-Sectional Study". JMSCR 03 (2015): 7199-7202.

6. Project in Biomedicine at ADBOU - University of Southern Denmark "Height Estimation from Skeletal, Remains". Mette Wod (2008).

7. Trotter M and Gleser G. "A re-evaluation of estimation of stature based on measurements taken during life and the long bones after death". American Journal of Physical Anthropology (1958).

8. Bass WM. Human Osteology - A Laboratory and Field Manual (2005).

Volume 2 Issue 11 November 2019

(C) All rights are reserved by Chansa Mulenga. 